\section{Advertisers in this issue:}

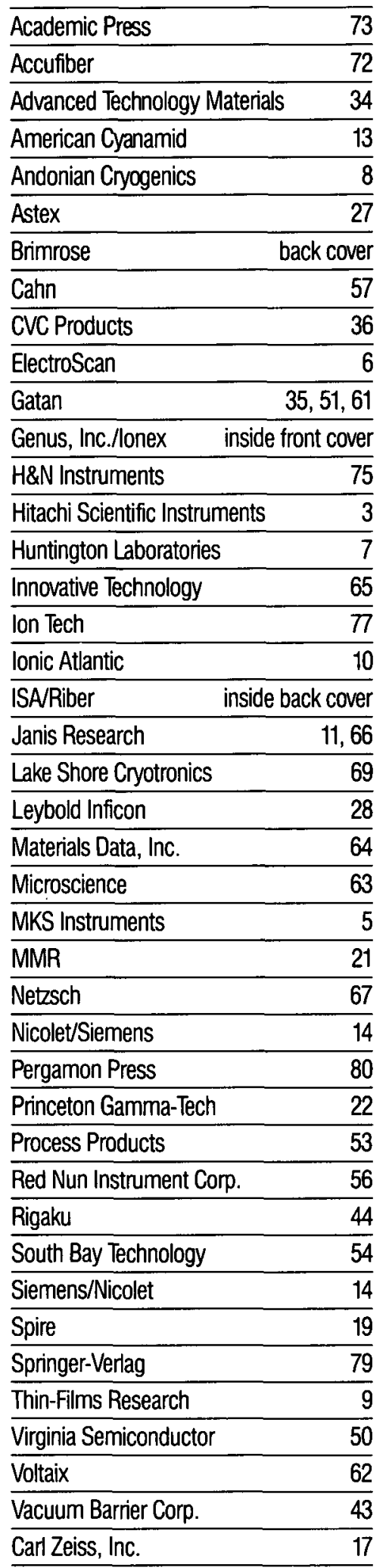

\title{
Materials Characterization
}

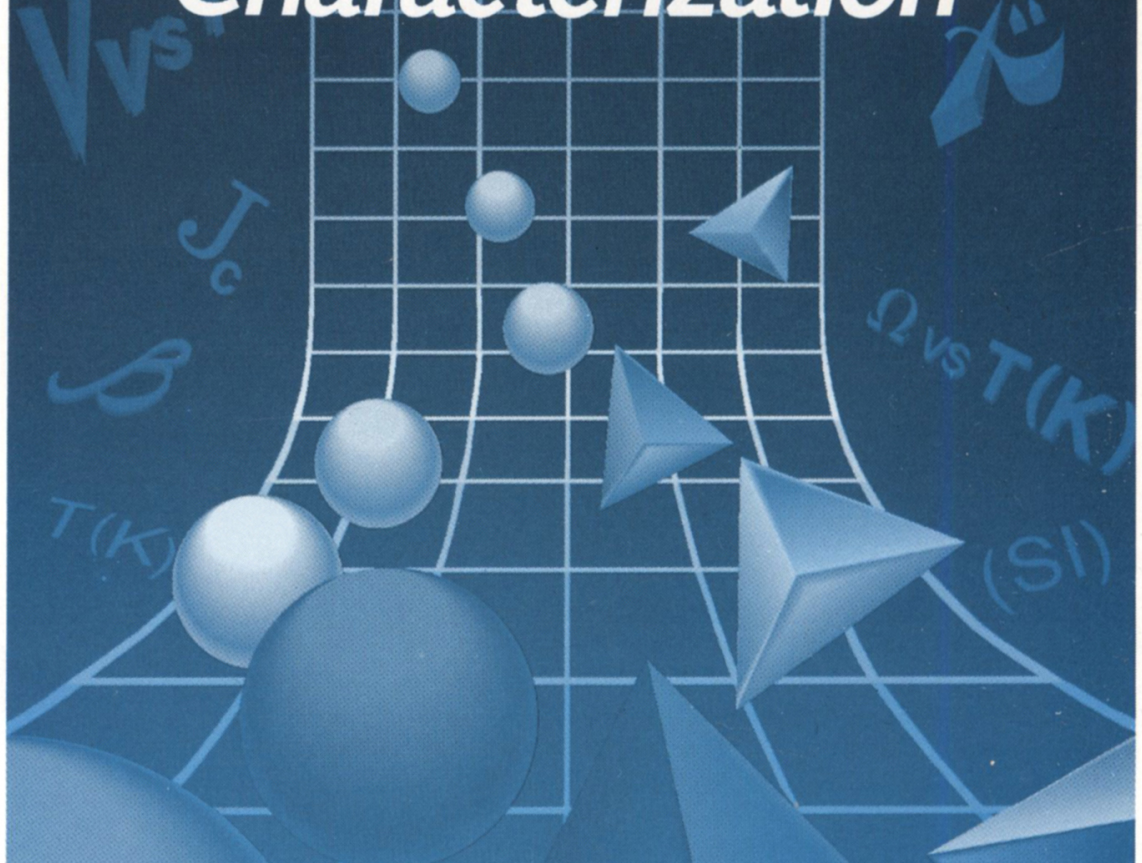

\section{Lake Shore. For characterization of conventional or high temperature superconductors and other magnetic property materials.}

For magnetic property measurements we introduce our new Model 7000 AC Susceptometer. The Model 7000 measures the magnetic susceptibility of ferromagnetic, paramagnetic and diamagnetic materials including bulk and thin film superconductors. It incorporates an option that measures $A C$ and $D C$ resistance versus temperature for all types of materials.

And soon, Lake Shore will introduce a noncontact temperature eddy current technique employing AC resistance to technology characterize superconductors.

Scientists and engineers continue to rely on Lake Shore products for precise control and measurement of temperature from $0.05 \mathrm{~K}\left(-273^{\circ} \mathrm{C}\right)$ to $800 \mathrm{~K}\left(527^{\circ} \mathrm{C}\right)$, both in zero field and in magnetic field environments to 19 tesla or higher.

Lake Shore. The choice for cryogenic temperature measurement and control, and now, transport measurements - AC susceptibility and $A C$ and DC resistance.

\section{LakeShore}

C R Y O T R N I C S, I N C.
64 East Walnut Street, Westerville, Ohio 43081 (614) $891-2243$
Telex: $24-5415$ Cryoton WTVL Fax: $(614) 891-1392$
Get measurable performance from Lake Shore's full line of sensors and sensor
calibration service.
(c) 1988 Lake Shore Cryotronics, Inc.

